\title{
Exploration and Reflection on MOOC Course of PE in China's Universities and Colleges under the Information Age
}

\author{
ZHANG Fan ${ }^{1,2} *$ \\ ${ }^{1}$ Department of Police Skills and Tactics, Nanjing Forest \\ Police College \\ ${ }^{2}$ Sports Science postdoctoral programme, Nanjing Normal \\ University \\ Nanjing 210023, China \\ zhangfan@nfpc.edu.cn
}

\author{
ZHOU Bo \\ Department of Police Skills and Tactics \\ Nanjing Forest Police College \\ Nanjing 210023, China \\ zhoubo@nfpc.edu.cn
}

\author{
JIA Chang-Zhi \\ Department of Police Skills and Tactics \\ Nanjing Forest Police College \\ Nanjing 210023, China \\ jichangzhi@nfpc.edu.cn
}

\begin{abstract}
As an emerging online education model, MOOC has caused an educational revolution all over the world. On the basis of a brief introduction to the characteristics of MOOC, this paper expounds the latest trends in the MOOC course of PE in Chinese colleges and universities. In addition, combined with the current reform of $P E$ course model, this paper discusses the Enlightenment of developing and applying PE MOOC course in China in the future. So as to provide reference for the reform of PE MOOC course model in China.
\end{abstract}

Keywords-MOOC; information age; online education; course model; PE

\section{INTRODUCTION}

Under the background of educational globalization and informationization, MOOC (Massive Open Online Courses), which is based on the concept of open sharing, has become an important trend of global education development. As an emerging educational model, not only has attracted a lot of media attention, it has aroused great interest in many institutions of higher education and commercial capital, but also brought great impact to the education and related industries. As an important component of the education system, the PE (physical education) course needs to relocate and deepen the reform in the new information environment so as to maintain and improve its own existing value and service scope. The MOOC course model will, on the one hand, bring great impact on the traditional teaching model of the PE course. On the other hand, it will exert a far-reaching influence on the teaching and reform of the PE course in colleges and universities.

\section{ANALYSIS OF THE CHARACTERISTICS OF MOOC}

MOOC is a new course model which has been proposed in recent years. In china, according to the pronunciation of MOOC, it has been called "Mu class". Through this innovative online course model, it is convenient for teachers to organize the content of the course, and then upload it to the Internet, so that students can register on the Internet, and then learn anytime, anywhere. Through the teaching practice, it has been observed that the application of MOOC online course model in Colleges and universities, with its opening characteristics, provides great convenience for PE. The interactive performance of this course model can improve students' enthusiasm and autonomy. MOOC also provides a new direction for the development and reform of the PE course. Through the application in the teaching of PE, MOOC greatly play it by time and space, and has characteristics of the strong interaction. MOOC is not confined to the classroom and the campus environment, which to some extent also promoted the reform of PE teaching methods. The following three aspects (motor technology, physical fitness practice, and interactive ways) analyze the characteristics of the MOOC course model.

\section{A. From the point of view of the characteristics of motor Technology}

MOOC can be explained by splitting video by a single technical action, or by combining action video. In the process of making video, we can through the network plane threedimensional pictures; animation, documentary and reality show multiple effects. So that students can clearly watch the action from multiple perspectives, and master the motor technical essentials [1]. Compared with the traditional demonstration teaching method, MOOC has the following advantages. (1) When students do not understand a technical action, they can 
watch, imitate and listen to it many times. (2) Students can listen, explain and imitate the action, so that they can avoid omitting details. (3) Students are free to choose learning sites and study time. (4) It is beneficial to the cultivation of students' learning autonomy, so the cultivation of good exercise habits also plays an active role in the formation of "lifelong exercise".

\section{B. From the point of view of physical fitness practice}

As each student has different physical qualities, the traditional form of collective teaching is difficult to balance the differences between students in these areas. And MOOC can better make up for this deficiency because students are free to choose what they want to learn according to their physical conditions.

\section{From the perspective of interactive ways}

MOOC is a kind of large-scale online courses, must fully take into account the interaction between course designers, course implementation and course learners in course design, so as to ensure the efficiency and convenience of the interaction. In the choice of interactive tools, because of the fragmentation of network learning, we can make full use of any social network chat tools (QQ, We Chat, blog, etc.), that teachers and students are familiar with and communicate with each other [2]. Through these chat software, not only in the stability and immediacy of the protection, but also can effectively improve the efficiency of interactive information transmission and teaching effectiveness, so as to effectively improve the effectiveness of classroom teaching.

\section{DISCUSSION ON THE APPLICATION OF MOOC COURSE IN PE IN CHINESE COLLEGES AND UNIVERSITIES}

\section{A. There is no deep integration between MOOC and PE}

How to encourage the deep integration of MOOC and PE has become an important topic in the field of $\mathrm{PE}$, and also a development trend of MOOC course research. Fusion of MOOC and PE teaching effect through students' learning depth to test the effect, but now the majority of PE teachers to understand the MOOC teaching mode is simple, that a simple combination of MOOC and PE teaching mode is MOOC. The majority of teachers are skeptical of MOOC, the information technology and equipment use efficiency are low, even skeptical of the new model, new technology, carry out informatization teaching in PE class effect is not ideal.

The inherent integration of MOOC and PE is to solve the problem that the application of information technology in $\mathrm{PE}$ has not been obvious for a long time, instead of simply improving some teaching contents and teaching methods. In fact, reform and innovation in PE teaching are inseparable from the emerging information-based course mode; effective MOOC mode must be the depth of integration and teaching methods, rather than just as to follow the prescribed order according to the design.

In addition, there is no fixed model for the integration of MOOC and PE. As long as it can adapt to the "MOOC+ PE" teaching mode and methods, teachers can hold an open and innovative attitude towards it.

\section{B. MOOC teaching requires a high level of information literacy for $P E$ teachers}

PE MOOC course design, development and implementation, not to make a few PE courseware. However, the use of multimedia technology does not mean that the MOOC course model will be used. In addition to mastering the necessary computer technology, PE teachers must follow the logic of the development of information technology courses in order to realize the change of teacher standard to the student standard in the future PE teaching. The need for PE teachers can skilled and fluent in the use of computers and other multimedia technology.

A PE course needs to be compressed into $10 \sim 15 \mathrm{~min}$ videos for students to learn, but also the need for some material which clips designed for teaching video and auxiliary data supporting the learning for students before class. In the course, it is necessary for PE teachers to design new forms of teaching organization according to the content of teaching, and guide students to study independently. There is also the maintenance of the later MOOC platform and the feedback of teaching information.

\section{The rate of completion of the MOOC course was low among the learners}

In 2013 and 2014, “www.guokr.com” launched two times for MOOC Chinese user questionnaire survey results show that users are bachelor degree or above, of which only $6 \%$ of all respondents completed the course, while $67 \%$ of respondents selected 1 courses are not complete; In the past two years, more students began using MOOC, of which about $50 \%$ of those surveyed did not complete a course. In the majority of respondents did not complete the course, mainly is the "time investment limited", " poor self-control or procrastination" and "language barrier", the reason is mostly subjective and not changed in 1 years [3]. In view of the above situation, the learners should make scientific learning strategies first when they come into contact with the MOOC course, instead of holding the mentality of trying to do online learning.

\section{The production and operation of MOOC courses require greater input}

As the core of a complex system, MOOC course is the teaching video, courseware and discussion area related to the subject of PE Teaching. The cost of making, managing and running MOOC is expensive. As an institution for teaching, educating and academic research, colleges and universities are not very suitable for leading MOOC, but they need a professional MOOC team to cooperate with each other. In addition, new union media (New Media Consortium, NMC) CEO Larry Johnson also said that the emergence of MOOC to promote worldwide knowledge sharing. However, MOOC can only partly replace university education, and can do nothing to teach some skills and emotional knowledge.

\section{E. MOOC course construction and operation level needs to be improved}

Compared with foreign countries, the development of MOOC in China is relatively late, and the number of courses is 
insufficient, the content of the course is insufficient and the ways of presentation are not sufficient to meet the diversified needs of the PE practice course. The MOOC course in Chinese universities lacks high-quality PE teaching resources, and the course system is still far from being established. The content of courses and training goals is not suitable, and the feedback is not good [4]. In addition, MOOC has many practical problems in the PE course, which makes the future construction and operation of MOOC course development must combine the characteristics of practice teaching and MOOC teaching mode. Therefore, the establishment of a unified course construction standards and improve the online education ecosystem, in order to promote the future of $\mathrm{PE} \mathrm{MOOC} \mathrm{course} \mathrm{standardization} \mathrm{and}$ standardization of teaching.

\section{ENLIGHTENMENT OF MOOC ON PE TEACHING IN CHINESE COLLEGES AND UNIVERSITIES}

\section{A. The appearance of MOOC has changed the traditional idea of PE Teaching}

With the development of large-scale online education, MOOC brings excellent PE resources to students through border less formal. The traditional PE course will also be transformed, and the focus of the future PE teachers will gradually be taught from simple knowledge and technology, to how to guide students to explore and think independently. Therefore, PE teachers need in order to change the traditional concept of PE in time.

In the face of future PE course reform in the process of MOOC have a sense of urgency, the single "teaching before" mode already cannot adapt to the current rapid development of information technology in education today [5]. MOOC allows students to learning resources from outside the traditional PE class and develop their self-learning ability. MOOC makes up for the lack of learning resources and skill displays in the traditional PE class, and realizes the new PE mode of "integrating both inside and outside the classroom". Through the MOOC platform, learners choose what they are interested in or use of knowledge.

This kind of study way that can choose content independently has realized the "teach students in accordance with their aptitude" that the traditional PE cannot realize, and the mass and excellent resources also meet the diversity and particularity of learners. In addition, universities should also increase $\mathrm{PE}$ teachers MOOC skills training, including the production of PE MOOC courses and the use of PE MOOC courses related to some teaching methods and evaluation methods.

\section{B. MOOC provides a good opportunity for the reform and development of $P E$}

Since 2012, MOOC courses have swept the world, which is an important event to promote international education informatization. The birth of MOOC is not only a change in form, but also a far-reaching impact on the development of PE in the future. MOOC as a new force, China's PE should be bold in changing the current teaching methods, improving the quality of subject teaching, and speeding up the integration of the PE course into the MOOC model.
On the one hand, the appearance of MOOC has a direct impact on the traditional concept and mode of higher PE. Colleges and universities should pay close attention to the trends and developments of large-scale online education in the world, and adopt reasonable and positive countermeasures [6]. On the other hand, University's enthusiasm for MOOC reflects the bottlenecks encountered in the reform of PE.

With the development of information technology, many PE courses, such as content, form, structure and so on, must be reformed. It can be seen that the teaching mode of PE in Colleges and universities will be more and richer in the future, and the practice and research of PE in Colleges and universities will be more and more. The space of PE will go from the traditional fixed site to the nature, and the study time will be extended from the classroom to the outside, and the form of learning will be more diverse.

\section{Attention should be paid to the unity of standardization and flexibility in the development of MOOC course in PE}

MOOC as an emerging network course model, its advantages are significant, such as the high quality of course content, the freedom of course dissemination, and more learners in the course. However, there are still some deficiencies in MOOC, such as the education level of the audience is inconsistent, unable to teach students in accordance with their aptitude, and cannot flexibly adjust the content of teaching according to the actual feedback. Therefore, in the development of PE MOOC courses, we need to absorb the existing advantages of MOOC and try to avoid deficiencies. In addition, in the future development of the PE course MOOC more and more, the need to establish a unified and standard of PE course construction MOOC standard, in order to promote the future of PE course MOOC standardization.

Such as relying on professional PE colleges or influential team of experts led the development of relevant standards, build a batch of domestic high level PE education course standard MOOC, and then gradually improve the MOOC course platform, forming a perfect MOOC teaching system. On the other hand, as PE course is not only divided into theoretical courses and practical courses, but also the contents of PE are various, and the characteristics of the courses are also very different. Therefore, in the formulation of relevant MOOC course standards also need according to the actual situation of course adjustment. Besides, PE teacher need not only to strengthen the feedback and adjustment in the running process of MOOC course, but also to continuous improvement, according to the actual teaching effect, in order to promote the future of the PE course standard and the flexibility of MOOC.

\section{Reconstructing the teaching methods and learning methods of PE MOOC course}

The idea determines behavior, which means that the educational concept decides the educational behavior. Many PE teachers have formed a fixed teaching paradigm and habit in the current traditional educational environment. At present, in the teaching of PE in many colleges and universities, teaching theory course is the main teaching method, and demonstrates to the students through PPT, maps and other forms [7]. This method of teaching is "cramming", and cannot adapt to the modern teaching requirements; the teaching 
method of practice course is a demonstration method, but teachers are restricted by various objective conditions such as age, gender, specialty and physical quality. In teacher's teaching, many technical movements are difficult to achieve standard demonstration, so that it is difficult for students to imitate exercises according to the teacher's explanation.

Therefore, it is necessary for PE teachers to change their concepts in time and have a sense of urgency in the process of facing the MOOC course reform in the future. Colleges and universities should also promptly train PE teachers MOOC skills, including the production of MOOC courses and the use of MOOC courses, new teaching methods, and evaluation methods. The reform of students' learning style must be matched with the reform of teaching methods. The MOOC course requires students to change from traditional knowledge. Skills and finishing learning of the knowledge based learning mode.

\section{CONCLUSION}

In the information age, the environment and conditions of higher education have changed, and the university PE course must advance with the times, so as to explore the new model, new methods and new ways of the university PE course. With the rapid development of information technology, the development of MOOC provides a new model for the traditional PE course, and also conforms to the needs of the reform of the PE course in colleges and universities. At the same time, we inevitably need to think about its ideals, and the contemporary pursuit of MOOC does not mean that the choice is correct. Similarly, the progress of information technology is not equal to the development of PE. MOOC should and always be a tool of "student aid", and it should be taken as the essential in the application of PE. MOOC technology is meant to promote the development of education, and PE teaching itself is the main body.

\section{ACKNOWLEDGMENT}

This work was supported in part by the Project of the Fundamental Research Funds for the Central Universities under Grant LGZD201709, in part by the Project of China Postdoctoral Science Foundation under Grant 2017M611849, in part by Jiangsu Qing LAN Project under Grant 2017, and in part by Nanjing Forest police College Teaching Reform Project under Grant ZD17001 \& YB17001.

\section{REFERENCES}

[1] Zhao Changhong, Ma Yanfen. MOOC. Development strategy of College $\mathrm{PE}$ in China. Journal of sports adult education, vol. 31, pp. 86-87, January 2015. (In Chinese)

[2] Zhang Yuejun, Du Peng, Yan Leilei. Analysis of college sports teaching under the background of MOOC. Contemporary sports science and technology, vol. 6, pp. 83-84, August 2016. (In Chinese)

[3] Cong Xiang Hui. Research on teaching reform of PE course in Colleges and Universities Based on MOOC. Journal of sports science and Technology Bulletin, vol. 24, pp. 71-72, July 2016. (In Chinese)

[4] Liu Liping, Chen Shanping, Sun Wei, et al. Course design of college PE theory MOOC. Modern sports science and technology, vol. 31, pp. 140142, June 2016. (In Chinese)

[5] Liu Jun. Construction and experimental study of MOOC flip classroom teaching mode. Journal of Guangzhou Sports University, vol. 36, pp. 121-123, February 2016. ( In Chinese)

[6] CHEN Jianwei. Online P.E. Course Construction in China's Universities and the Development Countermeasures in MOOC Era. Journal of Chengdu Sport University, vol. 41, pp. 109-114, June 2015. ( In Chinese)

[7] Cong Xianghui. Study on College Physical Education Curriculum Reform Based on MOOC Bulletin of Sport Science \& Technology, vol. 24, pp. 71-7, July 2016. ( In Chinese) 